\title{
Highly Sensitive Electrochemical Detection of Folic Acid by Using a Hollow Carbon Nanospheres@molybdenum Disulfide Modified Electrode
}

\author{
Huiming Ye, ${ }^{* 1 \dagger}$ Liang Song, ${ }^{* 2, * 3}$ Fuhui Zhang, ${ }^{* 1}$ Juan LI, ${ }^{* 1}$ Zhiying Su, ${ }^{* 4 \dagger}$ and Yun Zhang $* 2, * 3, * 5 \dagger$ \\ *1 Department of Clinical Laboratory, Women and Children's Hospital, School of Medicine, Xiamen University \\ *2 CAS Key Laboratory of Design and Assembly of Functional Nanostructures, and Fujian Provincial Key \\ Laboratory of Nanomaterials, Fujian Institute of Research on the Structure of Matter, Chinese Academy of \\ Sciences, Fuzhou, China \\ *3 Department of Translational Medicine, Xiamen Institute of Rare-earth Materials, Haixi Institutes, Chinese \\ Academy of Sciences, Xiamen, China \\ *4 Department of Obstetrics and gynecology, Women and Children's Hospital, School of Medicine, Xiamen \\ University \\ *5 University of Chinese Academy of Sciences, Beijing, China
}

\begin{abstract}
As a nutrient in body functions, folic acid (FA) plays a very important role for human health, and thus developing a highly sensitive method for its determination is of great significance. In the present work, carbon hollow nanospheres decorated with molybdenum disulfide nanosheets $\left(\mathrm{CHN} @ \mathrm{MoS}_{2}\right)$ nanomaterials were produced through a simple method and adopted to modify a glassy carbon electrode for assembling a highly sensitive electrochemical sensor of FA. After characterizing the prepared nanomaterials using scanning-/transmission-electron microscopy and Raman spectra, as well as optimizing various testing conditions, including the $\mathrm{pH}$ value of the buffer solution, the accumulation time and amount of nanomaterials on electrode surface, and the electrochemical determination of FA was carried out using a CHN@ $\mathrm{MoS}_{2}$ electrode. Owing to the coordinative advantages from CHN and $\mathrm{MoS}_{2}$, the results show that CHN@MoS 2 exhibits excellent sensing responses for FA, and it has a wide linear range from 0.08 to $10.0 \mu \mathrm{M}$ coupled with a low detection limit of $0.02 \mu \mathrm{M}$. Finally, the proposed method for FA detection was successfully applied in human urine analysis. The obtained results are satisfactory, revealing that the developed method based on $\mathrm{CHN} @ \mathrm{MoS}_{2}$ nanomaterials has important applications for FA determination.
\end{abstract}

Keywords Folic acid, hollow carbon nanospheres, electrochemical determination, molybdenum disulfide, nanomaterials, sensors

(Received August 8, 2020; Accepted September 24, 2020; Advance Publication Released Online by J-STAGE October 2, 2020)

\section{Introduction}

As an indispensable nutrient for the body functions, folic acid (FA), also called vitamin $\mathrm{B}_{9}$, is very vital during the periods of rapid cell growth and division. ${ }^{1,2}$ It is also crucial to produce red blood cell, to improve brain health and hearing loss and to synthesize and repair DNA/RNA. A lack of FA can arouse various numerous diseases such as megaloblastic anemia, cancer, metabolic syndromes, disorders hypertension and diabetes. For pregnant women, FA is a necessary nutrient to avoid the fetus from causing malformations of a skull, spine and brain..$^{3-5}$ Consequently, developing a simple and reliable method for detecting FA is very important.

Presently, several kinds of methods including fluorescence,

H. Y. and L. S. contributed equally to this work.

$\dagger$ To whom correspondence should be addressed.

E-mail: dyyyszy@126.com (Z. S.); zhangy@ fjirsm.ac.cn (Y.Z.); yehuiming@xmu.edu.cn (H. Y.) ultra-performance liquid chromatography, spectrophotometry, HPLC and electrochemical techniques have been proposed to detect FA. ${ }^{6-8}$ Among these methods, the electrochemical techniques have attracted a lot of attentions, resulting from their distinctive advantages, such as simple operation, low-cost, high reproducibility and rapid response. ${ }^{9-11}$ For instance, Wang and his colleagues ${ }^{10}$ prepared $\mathrm{ZrO}_{2} / \mathrm{ZnO}$ nanocomposites for sensing FA electrochemically. The related results revealed that a $\mathrm{ZrO}_{2} /$ $\mathrm{ZnO}$ modified electrode has a linear range of from 2.0 to $400.0 \mu \mathrm{M}$ and a detection limit (LOD) of $0.037 \mu \mathrm{M}$. In another work, Jost et al. ${ }^{11}$ prepared a carbon nanotubes/nickel hydroxide nanocomposite. They used it to construct an electrochemical sensor of FA. The linear range was from 0.5 to $26.0 \mu \mathrm{M}$ and had a LOD of $0.095 \mu \mathrm{M}$. Although these methods for detecting FA are very important, achieving highly sensitive and reliable detection of FA is still a great challenge.

For achieving efficient and sensitive determination, the employed materials for modifying the electrode are a key factor in electrochemical sensing. ${ }^{12-15}$ Molybdenum disulfide $\left(\mathrm{MoS}_{2}\right)$ nanosheet, a 2D transition metal dichalcogenide, exhibits a 

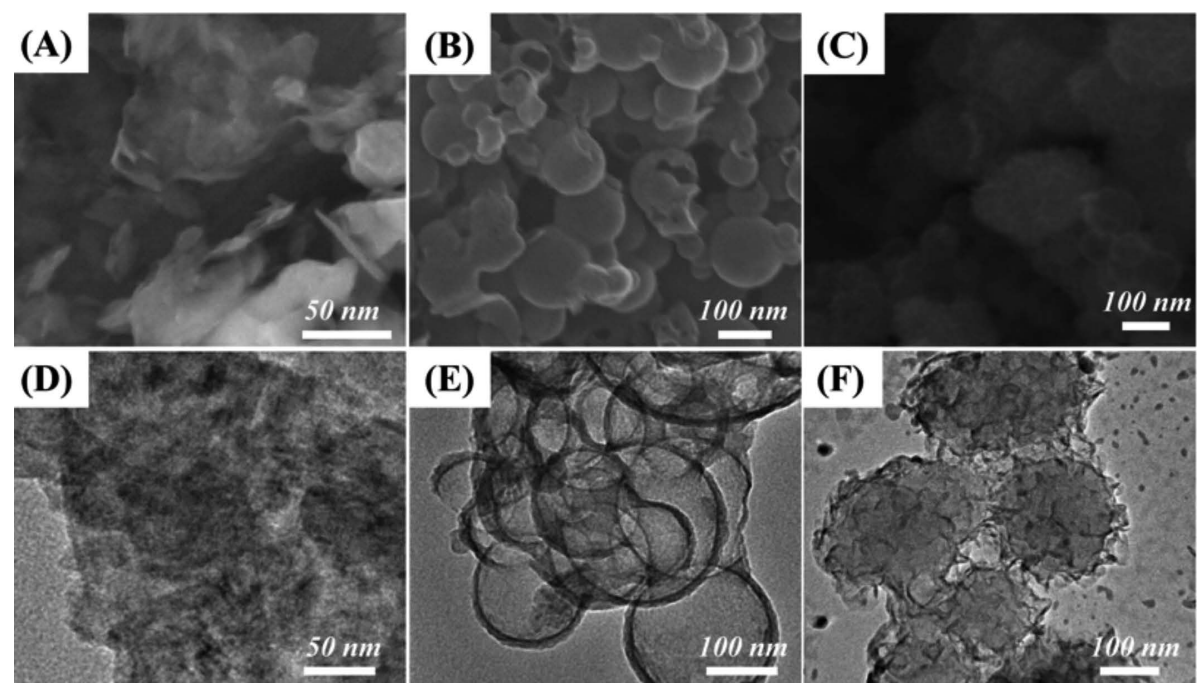

Fig. 1 SEM images of $\mathrm{MoS}_{2}$ (A), CHN (B), and CHN@ $\mathrm{MoS}_{2}$ (C); TEM images of $\mathrm{MoS}_{2}$ (D), CHN (E), and CHN@ $\mathrm{MoS}_{2}(\mathrm{~F})$.

graphene-like layered nanostructure, and constituted a Mo layer sandwiched between 2 sulfur layers. ${ }^{16-19}$ It possesses many interesting characteristic properties (e.g., excellent catalytic ability, low cost, design flexibility, abundant marginal active sites). Presently $\mathrm{MoS}_{2}$ nanosheets have received extensive attentions in many fields. ${ }^{20-22}$ Meanwhile, some reports have indicated the advantages of $\mathrm{MoS}_{2}$ nanosheet enables it to be one of the promising nanomaterials for developing next-generation electrochemical sensors. ${ }^{23}$ This makes us believe that $\mathrm{MoS}_{2}$ can be selected to construct a highly sensitive electrochemical sensor for FA. However, pure $\mathrm{MoS}_{2}$ nanosheets are easy to stack with each other, and its conductivity is not desirable. ${ }^{24-29}$

For overcoming the $\mathrm{MoS}_{2}$ defects and improving its practical performance, integrating $\mathrm{MoS}_{2}$ nanosheets with carbon materials is considered to be an ideal project, because the formed nanostructures can exhibit specific coordinative properties of each component to avoid $\mathrm{MoS}_{2}$ stacking and to enhance the electrochemical properties. ${ }^{30-34}$ Hollow carbon nanospheres $(\mathrm{CHN})$ are a desirable candidate to integrate $\mathrm{MoS}_{2}$ nanosheets due to the high surface area, conductivity and stability. In this work, for achieving a highly sensitive determination of FA, $\mathrm{CHN}$ decorated with $\mathrm{MoS}_{2}$ nanosheets $\left(\mathrm{CHN} @ \mathrm{MoS}_{2}\right)$ nanomaterials was synthesized firstly via a simple and green method, and CHN@ $\mathrm{MoS}_{2}$ was then applied to modify a GCE to assemble an electrochemical sensor (CHN@ $\left.\mathrm{MoS}_{2} / \mathrm{GCE}\right)$ of FA. The experimental results showed that $\mathrm{CHN} @ \mathrm{MoS}_{2} / \mathrm{GCE}$ exhibits much higher sensing performances than pure $\mathrm{CHN}$ or $\mathrm{MoS}_{2}$ modified GCE resulting from synergetic effects due to $\mathrm{MoS}_{2}$ and CHN. Importantly, after optimizing various conditions, a wide linear range and low LOD were achieved by CHN@ $\mathrm{MoS}_{2} / \mathrm{GCE}$ for FA. It is expected that the developed electrochemical method for detecting FA has important applications in the analysis of real samples.

\section{Experimental}

\section{Synthesizing CHN@MoS}

CHN was firstly prepared according to previous work. ${ }^{35}$ Then, $\mathrm{CHN}$ was added into ultrapure water and ultrasonicated for some minutes, and L-cysteine/ $\mathrm{Na}_{2} \mathrm{MoO}_{4}$ was added to $\mathrm{CHN}$ dispersion via stirring. Next, the formed mixture was moved in a Teflon-autoclave to be heated for $12 \mathrm{~h}$ at $200^{\circ} \mathrm{C}$, and the autoclave was left further to cool down. The produced CHN@ $\mathrm{MoS}_{2}$ nanohybrd was collected via centrifugation and cleaned with water/ethanol, and was then dried overnight. Finally, the prepared CHN@ $\mathrm{MoS}_{2}$ was annealed in a $\mathrm{N}_{2}$ atmosphere at high temperature. For a comparison, the pure $\mathrm{MoS}_{2}$ nanosheets were prepared by similar processes.

\section{Preparing CHN@MoS$/$ /GCE and electrochemical texts}

The GCE surface was carefully polished with $0.05-/ 0.5-\mu \mathrm{m}$ alumina, respectively, and then cleaned with ultrapure water, followed by cleaning ultrasonically in acetone and ultra-pure water, respectively. Then $2.0 \mathrm{mg} \mathrm{CHN} @ \mathrm{MoS}_{2}$ was added into $4.0 \mathrm{~mL}$ of ultrapure water and sonicated for $20 \mathrm{~min}$ to form a homogeneous suspension. CHN@ $\mathrm{MoS}_{2} / \mathrm{GCE}$ was prepared by dropping different amounts of a $\mathrm{CHN} @ \mathrm{MoS}_{2}$ suspension on the GCE surface. For a comparison, $\mathrm{MoS}_{2} / \mathrm{GCE}$ and $\mathrm{CHN} / \mathrm{GCE}$ were prepared through similar steps. The electrochemical sensing of $\mathrm{CHN} @ \mathrm{MoS}_{2} / \mathrm{GCE}$ towards FA was carried out following 2 consecutive processes: (i) the pre-concentration of FA to the electrode surface with certain of accumulation time; and (ii) measuring with electrochemical technologies.

\section{Results and Discussion}

\section{Characterization of the CHN@ $\mathrm{MoS}_{2}$}

Scanning- and transmission-electron microscopy (SEM, TEM) were used to investigate the structures and morphologies of CHN@ $\mathrm{MoS}_{2}$ and related nanomaterials. As depicted in Fig. 1(A), the pure $\mathrm{MoS}_{2}$ nanosheets tend to agglomerate with each other. Figure 1(B) exhibits a SEM image of pure CHN; it's noted that $\mathrm{CHN}$ is distributed uniformly with a hollow structure and a smooth surface. As for CHN@ $\mathrm{MoS}_{2}$ (Fig. 1(C)), it can be found that the $\mathrm{MoS}_{2}$ nanosheets loosely wrap with the CHN surface, showing flower-like nanostructures. Figures $1(\mathrm{D})$ to $1(\mathrm{~F})$ show TEM images of MoS2 (Fig. 1(D)), CHN (Fig. 1(E)) and CHN@ $\mathrm{MoS}_{2}$ (Fig. 1(F)). As shown in Fig. 1(D), the pure $\mathrm{MoS}_{2}$ tends to stack tightly together with an interlaced nanostructure. For $\mathrm{CHN}$, the hollow structures are observed visibly with a thickness of the $10 \mathrm{~nm}$ carbon layer, which could offer a large surface area for loading $\mathrm{MoS}_{2}$ nanosheets. As for the CHN@MoS 


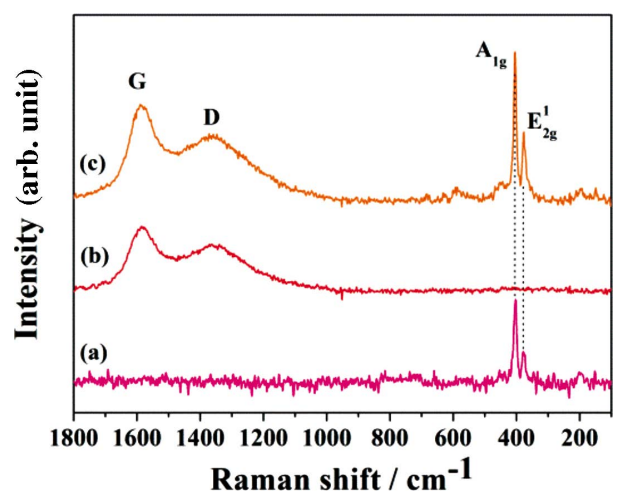

Fig. 2 Raman spectra of $\mathrm{MoS}_{2}$ (a), CHN (b) and CHN@ $\mathrm{MoS}_{2}$ (c).

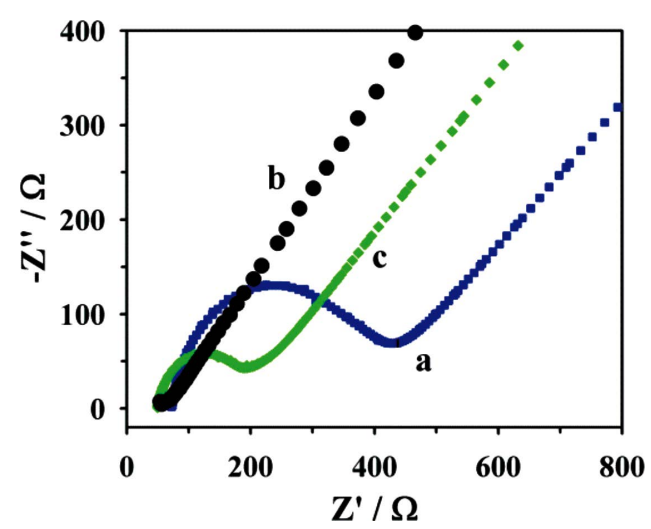

Fig. 3 EIS plots of the $\mathrm{MoS}_{2} / \mathrm{GCE}$ (a), CHN/GCE (b), and CHN@ $\mathrm{MoS}_{2} / \mathrm{GCE}$ (c) recorded in a $\mathrm{Fe}(\mathrm{CN})_{6}^{3-14-}$ solution.

hybrids (Fig. 1(F)), CHN as a substratum affords more attachment sites for supporting the formation and impeding the agglomeration of $\mathrm{MoS}_{2}$ nanosheets; hence, it can be noted that $\mathrm{MoS}_{2}$ sheets are uniformly dispersed on the CHN surface, of which the result is inconsistent with the former SEM characterization.

Raman spectra were further used to study the prepared CHN@ $\mathrm{MoS}_{2}$ and related nanohybrids (Fig. 2). For pure $\mathrm{MoS}_{2}$ and the prepared $\mathrm{CHN} @ \mathrm{MoS}_{2}$, there are 2 distinct peaks at $\sim 405.0$ and $377.0 \mathrm{~cm}^{-1}$ ascribed to the out-of-plane $A_{1 \mathrm{~g}}$ phonon modes and in-plane from $\mathrm{MoS}_{2}$, respectively. For CHN and $\mathrm{CHN} @ \mathrm{MoS}_{2}$ materials, the 2 characteristic peaks presented at $\sim 1590$ and $1340 \mathrm{~cm}^{-1}$ correspond to the $\mathrm{G}$ and $\mathrm{D}$ band, respectively, owing to the presence of carbon. The intensity proportion of the $\mathrm{D}$ and $\mathrm{G}$ bands (denoted as $I_{\mathrm{D}} / I_{\mathrm{G}}$ ) is frequently used to assess the graphitization degree in carbon nanomaterials. ${ }^{36}$ The figure shows that the relative intensity from the $G$ band is stronger compared to the $\mathrm{D}$ band, suggesting that $\mathrm{CHN}$ is well graphitized via the calcining step. Meanwhile, the $I_{\mathrm{D}} / I_{\mathrm{G}}$ value from $\mathrm{CHN} @$ $\mathrm{MoS}_{2}$ is even smaller than that from CHN, attributed to twotime annealing. These results indicate that $\mathrm{CHN} @ \mathrm{MoS}_{2}$ nanomaterials were produced successfully.

Next, the electrochemical impedance technique was adopted to study the electron transfer behaviors in various electrodes. Figure 3 shows the corresponding impedance spectroscopy (EIS) of $\mathrm{MoS}_{2} / \mathrm{GCE}$ (a), CHN/GCE (b) and CHN@ $\mathrm{MoS}_{2} / \mathrm{GCE}$ (c) recorded in a $5.0 \mathrm{mM}\left[\mathrm{Fe}(\mathrm{CN})_{6}\right]^{3-/ 4-}$ solution. Through simulating the EIS data using a Randles equivalent circuit, it can

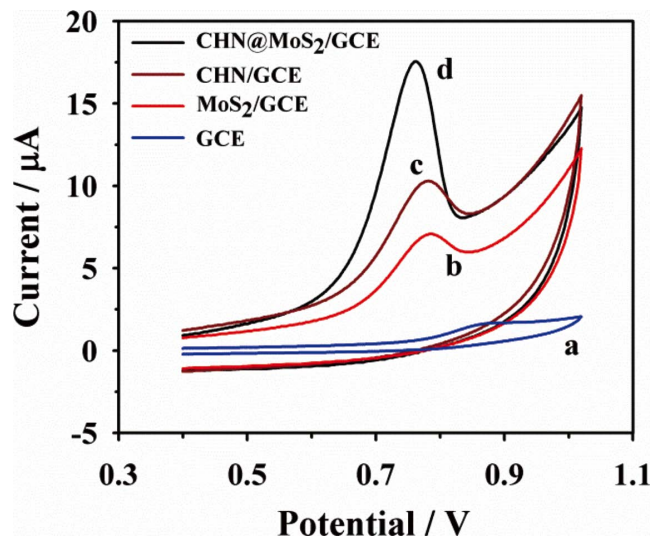

Fig. $4 \mathrm{CV}$ responses of $25.0 \mu \mathrm{M}$ FA at (a) GCE, (b) $\mathrm{MoS}_{2} / \mathrm{GCE}$, (c) CHN/GCE, and (d) CHN@ $\mathrm{MoS}_{2} / \mathrm{GCE}$ in $0.1 \mathrm{M}$ PBS.

be known the charge-transfer resistance $\left(R_{\mathrm{CT}}\right)$ of $\mathrm{MoS}_{2} / \mathrm{GCE}$ $(\sim 350.0 \Omega)$ is larger than those from the other electrodes, since the conductivity of pure $\mathrm{MoS}_{2}$ nanosheet is not desirable, while the $R_{\mathrm{CT}}$ value of $\mathrm{CHN}$ is considerable small, and it can even be neglected, suggesting that the electron transfer rate in $\mathrm{CHN}$ is very high. It is worth noting that $\mathrm{CHN} @ \mathrm{MoS}_{2} / \mathrm{GCE}$ has a much lower $R_{\mathrm{CT}}$ value $(\sim 130.0 \Omega)$ compared to $\mathrm{MoS}_{2} / \mathrm{GCE}$, indicating the introduction of $\mathrm{CHN}$ could obviously improve the conductivity of $\mathrm{MoS}_{2}$-based nanomaterials.

\section{Electrochemical behaviors of FA}

The electrochemical behaviors of FA at $\mathrm{CHN} @ \mathrm{MoS}_{2} / \mathrm{GCE}$ and the related modified electrodes were studied by cyclic voltammetry $(\mathrm{CV})$ technology in a $0.1 \mathrm{M}$ phosphate buffer solution (PBS, $\mathrm{pH} 7.0$ ). As depicted in Fig. 4, the $\mathrm{CV}$ response of FA at GCE shows a weak and broad oxidation peak located at $0.85 \mathrm{~V}$, while $\mathrm{MoS}_{2} / \mathrm{GCE}$ shows an apparently increased oxidation peak current, which is much stronger than that at GCE resulting from the high catalytic ability and abundant marginal active sites of $\mathrm{MoS}_{2}$. Owing to the high surface area and the prominent electrochemical activity of CHN, CHN/GCE also shows a much larger oxidation current than bare GCE. Interestingly, it is noted that the peak current value of FA at $\mathrm{CHN} @ \mathrm{MoS}_{2} / \mathrm{GCE}$ displays a significant increase compared to all of the other modified electrodes, and the oxidation potential was shifted to $0.73 \mathrm{~V}$ negatively; specifically, the current value at $\mathrm{CHN} @ \mathrm{MoS}_{2} / \mathrm{GCE}$ is $\sim 16.1, \sim 3.3$ and $~ 2.6$-times higher than those at GCE, $\mathrm{MoS}_{2} / \mathrm{GCE}$ and $\mathrm{CHN} / \mathrm{GCE}$, respectively. This implies that $\mathrm{CHN} @ \mathrm{MoS}_{2} / \mathrm{GCE}$ can exhibit the coordinative advantages from $\mathrm{MoS}_{2}$ and $\mathrm{CHN}$ for electrochemically detecting FA, which is expected to possess promising applications for constructing a highly sensitive electrochemical sensor of FA.

\section{Optimization of the conditions}

As a powerful electrochemical technology, differential pulse voltammetry (DPV), has a higher sensitivity and resolution compared to $\mathrm{CV}$ technology. For achieving a highly sensitive determination of FA based on $\mathrm{CHN} @ \mathrm{MoS}_{2} / \mathrm{GCE}$, various experimental text conditions were optimized by DPV; the related results are exhibited in Fig. 5.

Firstly, the influence from the $\mathrm{pH}$ value of PBS was studied over $\mathrm{pH}$ values from 4.0 to 9.0 (Fig. 5(A), accumulation time of $50 \mathrm{~s}$; amount of CHN@ $\mathrm{MoS}_{2} 10.0 \mu \mathrm{L}$ ). It is noted from the figure that the oxidation current of FA keeps increasing along with the increase of the $\mathrm{pH}$ value from 4.0 to 7.0 , while it begins 

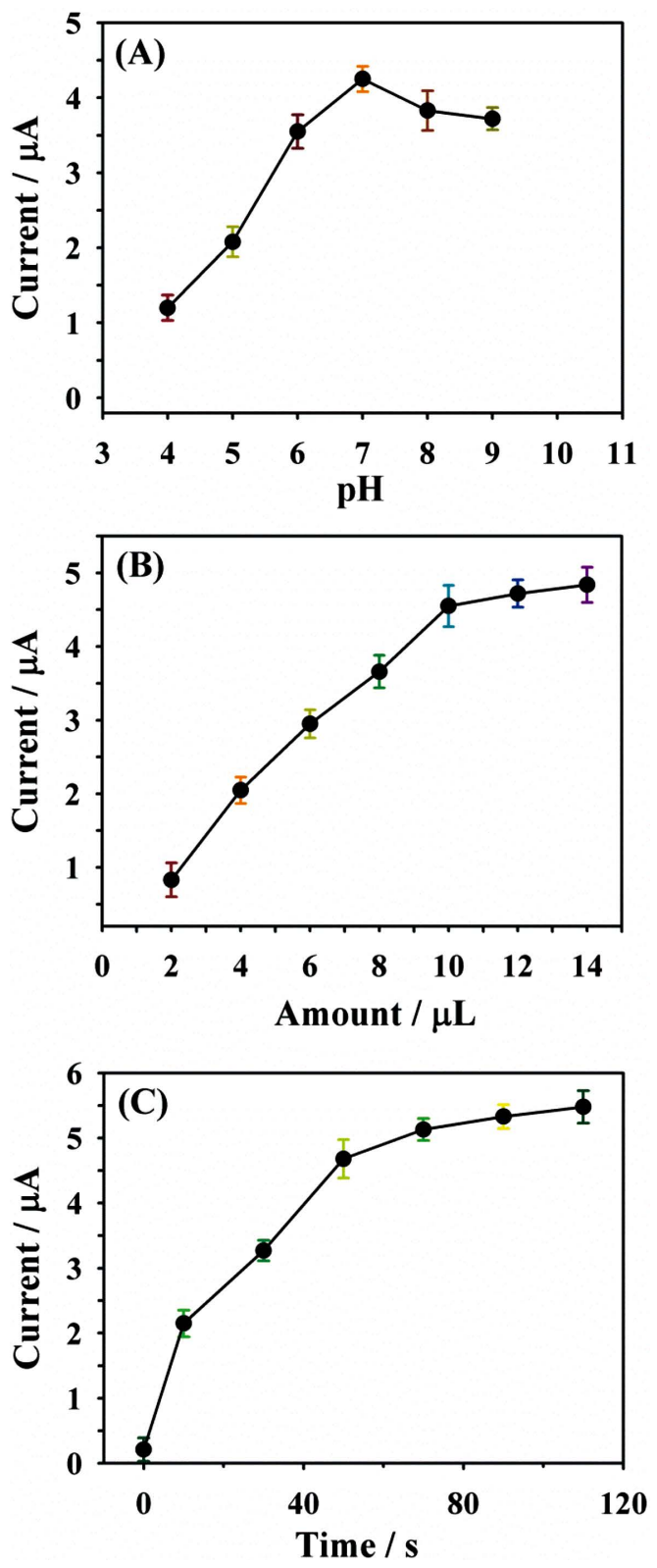

Fig. 5 Influence of the $\mathrm{pH}$ value (A), amount of $\mathrm{CHN} @ \mathrm{MoS}_{2}(\mathrm{~B})$ and accumulation time $(\mathrm{C})$ on the DPV peak current of $5.0 \mu \mathrm{M}$ FA at $\mathrm{CHN} @ \mathrm{MoS}_{2} / \mathrm{GCE}$

to reduce when the $\mathrm{pH}$ value increases further to 9.0 since protons are involved in FA oxidation. For achieving high sensitivity, a $\mathrm{pH}$ of 7.0 was selected in following experiments. Next, the influence from the amount of $\mathrm{CHN} @ \mathrm{MoS}_{2}$ nanomaterials on the electrode surface was also studied (Fig. 5(B)), it can be found that the oxidation current from FA obviously increases along with the increase of the CHN@ $\mathrm{MoS}_{2}$ suspension amount $\left(0.5 \mathrm{mg} \mathrm{mL}^{-1}\right)$ from 2.0 to $1.0 \mu \mathrm{L}$. As for the amount from 10.0 to $14.0 \mu \mathrm{L}$, the peak current shows only weak increases. Hence, $10.0 \mu \mathrm{L}$ as the optimum amount was applied throughout the work. There is no doubt that the sensing sensitivity is affected by the accumulation time; thus, the influence from the accumulation time was also investigated. As shown in Fig. 5(C), the oxidation current of FA increases with the increase of the accumulation time, obtaining a maximum at $50 \mathrm{~s}$; hence, this time was used as the optimal value time in the study.
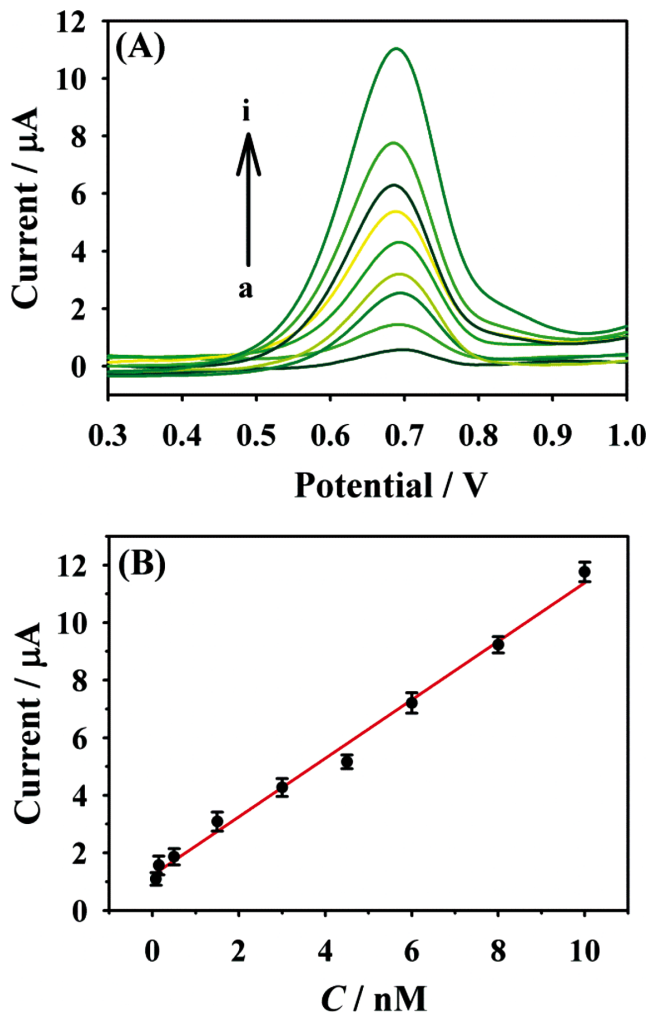

Fig. 6 (A) DPV responses of $\mathrm{CHN} @ \mathrm{MoS}_{2} / \mathrm{GCE}$ in $0.1 \mathrm{M}$ PBS containing various concentrations of FA from 0.08 to $10.0 \mu \mathrm{M}$. (B) Corresponding standard curve of FA.

Table 1 Comparison of the proposed CHN@ $\mathrm{MoS}_{2} / \mathrm{GCE}$ with the reported electrochemical sensors in previous literature for detecting FA

\begin{tabular}{|c|c|c|c|}
\hline Materials used & Linear range $/ \mu \mathrm{M}$ & $\mathrm{LOD} / \mu \mathrm{M}$ & Ref. \\
\hline $\mathrm{Co}_{3} \mathrm{O}_{4} / \mathrm{rGO} / \mathrm{CTAB}$ & $500.0-3200.0$ & 95.0 & 2 \\
\hline $\begin{array}{l}\text { Polyortho-methoxyaniline/ } \\
\text { carbon nanodots }\end{array}$ & $0.5-68.0$ & 0.113 & 3 \\
\hline $\begin{array}{l}\text { Molecularly imprinted } \\
\text { poly( } p \text {-aminobenzene- } \\
\text { sulphonic acid }) / \text { carbon } \\
\text { nanodots }\end{array}$ & $0.0049-0.0698$ & 0.0045 & 4 \\
\hline $\begin{array}{l}\text { Au nanoclusters/graphene/ } \\
\text { carbon nanodots }\end{array}$ & $10.0-170.0$ & 0.1 & 9 \\
\hline $\mathrm{ZrO}_{2} / \mathrm{ZnO}$ & $2.0-400.0$ & 0.037 & 10 \\
\hline $\begin{array}{l}\text { Carbon nanotubes/nickel } \\
\text { hydroxide }\end{array}$ & $0.5-26.0$ & 0.095 & 11 \\
\hline $\mathrm{CHN} @ \mathrm{MoS}_{2}$ & $0.08-10.0$ & 0.02 & This work \\
\hline
\end{tabular}

Analytical performance of $C H N @ M_{2} / G C E$

Under the above optimal conditions, the analytical performance of $\mathrm{CHN} @ \mathrm{MoS}_{2} / \mathrm{GCE}$ toward FA was evaluated by plotting the related calibration curve containing the changes from the DPV peak currents upon the increase from the FA concentration, it is found that the peak current of FA linearly increases with the FA concentration, ranging from 0.08 to $10 \mu \mathrm{M}$ (Fig. 6). The corresponding linear regression equation is defined as $I_{\mathrm{p}}(\mu \mathrm{A})=$ $1.215+1.017 C(\mu \mathrm{M})$, coupled with the correlation coefficient of $R^{2}=0.9964 ;$ the LOD is calculated to be $0.02 \mu \mathrm{M}(S / N=3)$. In addition, the proposed detection method for FA in the work is compared with previous studies (Table 1). The comparative 
Table 2 Detection of FA in real urine samples

\begin{tabular}{ccccc}
\hline Sample & Added $/ \mu \mathrm{M}$ & Found $/ \mu \mathrm{M}$ & RSD, \% & Recovery, \% \\
\hline 1 & 0.5 & 0.53 & 3.55 & 106.0 \\
2 & 2.0 & 1.92 & 4.36 & 96.0 \\
3 & 5.0 & 5.25 & 5.72 & 105.0 \\
4 & 8.0 & 7.88 & 3.83 & 98.5 \\
\hline
\end{tabular}

results indicate that $\mathrm{CHN} @ \mathrm{MoS}_{2} / \mathrm{GCE}$ has lower LOD and wider linear range than most of the previous studies, meanwhile it possesses wide linear resulting from abundant marginal active sites and large surface of $\mathrm{CHN} @ \mathrm{MoS}_{2}$, suggesting that it can be used in a highly sensitive determination for FA. It should also be pointed out that the preparation method for $\mathrm{CHN} @ \mathrm{MoS}_{2}$ is simple, low cost and green.

\section{Reproducibility, stability and selectivity}

For evaluating the CHN@ $\mathrm{MoS}_{2} / \mathrm{GCE}$ reproducibility, which is expressed via the relative standard deviation (RSD), six parallelmade CHN@ $\mathrm{MoS}_{2} / \mathrm{GCE}$, were used to measure $5.0 \mu \mathrm{M}$ FA by DPV. The RSD value of the peak current response was found to be $4.36 \%$. On other hand, the long-term stability of CHN@ $\mathrm{MoS}_{2} / \mathrm{GCE}$ was evaluated via testing the peak current response of FA for thirty days with an interval of six days. The results show that CHN@ $\mathrm{MoS}_{2} / \mathrm{GCE}$ maintained 95.6\% of the initial current response. These results demonstrated that $\mathrm{CHN} @ \mathrm{MoS}_{2}$ GCE has an acceptable reproducibility and store stability.

The selectivity of CHN@ $\mathrm{MoS}_{2} / \mathrm{GCE}$ for FA was evaluated by comparing current responses in the presence of potential interfering organic molecules. The results reveal that no evident interference was presented for the following molecules including methotrexate, ascorbic acid, folinic acid, tetrahydofolic acid, uric acid, 5-methyltetrahydrofolate, dopamine and pyridoxine (10 times of FA concentration), suggesting that the CHN@ $\mathrm{MoS}_{2} / \mathrm{GCE}$ has a satisfactory selectivity for FA analysis.

\section{Real samples analysis}

For evaluating the feasibility of $\mathrm{CHN} @ \mathrm{MoS}_{2} / \mathrm{GCE}$ in practical applications, FA in human urine was determined by the developed method. First, the urine samples were centrifuged, extracted and diluted with PBS, and sequentially the original content of FA in the urine sample was measured by the proposed method. The results show that there was no FA detected. Next, the samples were spiked with various concentrations of FA and the peak current of FA was recorded by CHN@ $\mathrm{MoS}_{2} / \mathrm{GCE}$; the recoveries were applied to evaluate the feasibility in real samples (Table 2). As depicted in Table 2, the obtained recoveries are found in the range from 96.0 to $106.0 \%$ and the RSD values are below 6.0\%, indicating that the proposed $\mathrm{CHN} @ \mathrm{MoS}_{2} / \mathrm{GCE}$ sensor can detect FA successfully in real samples.

\section{Conclusions}

In summary, a novel electrochemical sensor for the highly sensitive detection of FA was successfully developed by preparing CHN@ $\mathrm{MoS}_{2}$ as electrode nanomaterials. The final results demonstrated that $\mathrm{CHN} @ \mathrm{MoS}_{2}$ could exhibit the coordinative advantages from $\mathrm{MoS}_{2}$ and $\mathrm{CHN}$ for FA analysis, and the prepared CHN@ $\mathrm{MoS}_{2} / \mathrm{GCE}$ shows excellent sensing performances with a wide linear range and a low LOD, Meanwhile, the developed $\mathrm{CHN} @ \mathrm{MoS}_{2} / \mathrm{GCE}$ exhibits high reproducibility and stability, as well as excellent selectivity and practicability. Furthermore, the proposed method for FA analysis is simple, low cost and green. It is confirmed that the developed method for FA detection based on $\mathrm{CHN} @ \mathrm{MoS}_{2}$ will have important potentials in real sample analysis.

\section{Acknowledgements}

This study was financed by the Major Program of main disease in Xiamen City by Xiamen Science and Technology Bureau and Xiamen Municipal Health Commission (No. 3502Z2017050); Joint Project of health education in Fujian Province (2019-WJ35) .

\section{References}

1. S. Akbar, A. Anwar, and Q. Kanwal, Anal. Biochem., 2016, 510, 98.

2. M. Venu, Int. J. Electrochem. Sci., 2018, 11702.

3. H. Rajabi, and M. Noroozifar, Mater. Sci. and Eng. C, 2017, 75, 791

4. S. Güney, J. Electroanal. Chem., 2019, 854, 113518.

5. F. Chekin, F. Teodorescu, Y. Coffinier, G.-H. Pan, A. Barras, R. Boukherroub, and S. Szunerits, Biosens. Bioelectron., 2016, 85, 807 .

6. W. Ren, Y. Fang, and E. Wang, ACS Nano, 2011, 5, 6425.

7. S. Ulusoy, H. Acıdereli, S. Erdoğan, and H. İbrahim Ulusoy, RSC Adv., 2016, 6, 40115.

8. X. Li and L. Chen, ACS appl. mater. interfaces, 2016, 8, 31832 .

9. A. A. Abdelwahab and Y. Shim, Sens. Actuators, 2015, 221, 659.

10. Q. Wang, H. Si, L. Zhang, L. Li, X. Wang, and S. Wang, Anal. Chim. Acta, 2020, 1104, 69.

11. J. P. Winiarski, R. Rampanelli, J. C. Bassani, D. Z. Mezalira, and C. L. Jost, J. Food Compos. Anal., 2020, 92, 103511.

12. Y. Yi, D. Zhang, Y. Ma, X. Wu, and G. Zhu, Anal. Chem., 2019, 91, 2908.

13. J. Hu, K. T. Ho, X. U. Zou, W. H. Smyrl, A. Stein, and P. Buhlmann, Anal. Chem., 2015, 87, 2981.

14. K. Hsieh, B. S. Ferguson, M. Eisenstein, K. W. Plaxco, and H. T. Soh, Acc. Chem. Res., 2015, 48, 911.

15. A. Kotani, M. Kaneko, K. Machida, K. Yamamoto, and H. Hakamata, Anal. Sci., 2020, 10.2116/analsci.2120p2049.

16. O. Parlak, A. Incel, L. Uzun, A. P. F. Turner, and A. Tiwari, Biosens. Bioelectron., 2017, 89, 545.

17. A. Sinha, Dhanjai, B. Tan, Y. Huang, H. Zhao, X. Dang, J. Chen, and R. Jain, TrAC, Trends Anal. Chem., 2018, 102, 75.

18. M. Sharifuzzaman, S. C. Barman, M. A. Zahed, N. J. San, and J. Y. Park, J. Electrochem. Soc., 2019, 166, B249.

19. D. Zhang, Y. Ma, O. J. Kingsford, J. Qian, and Y. Yi, J. Electrochem. Soc., 2019, 166, B1392.

20. B. Mao, B. Wang, F. Yu, K. Zhang, Z. Zhang, J. Hao, J. Zhong, Y. Liu, and W. Shi, Int. J. Hydrogen Energy, 2018, 43, 11038.

21. L. Xing and Z. Ma, Microchim. Acta, 2015, 183, 257.

22. Y. Wang, G. Ning, H. Bi, Y. Wu, G. Liu, and Y. Zhao, Electrochim. Acta, 2018, 285, 120.

23. S. K. Tuteja, T. Duffield, and S. Neethirajan, Nanoscale, 2017, 9, 10886.

24. S. Wang, B. Y. Guan, L. Yu, and X. W. D. Lou, Adv. Mater., 2017, 29

25. L. Song, X. Wang, F. Wen, L. Niu, X. Shi, and J. Yan, Int. 
J. Hydrogen Energy, 2016, 41, 18942.

26. P. Jing, H. Yi, S. Xue, Y. Chai, R. Yuan, and W. Xu, Anal. Chim. Acta, 2015, 853, 234.

27. A. Ambrosi, Z. Sofer, and M. Pumera, Small, 2014, 11 , 605.

28. A. S. Subramanian, J. N. Tey, L. Zhang, B. H. Ng, S. Roy, J. Wei, and X. M. Hu, Polymer, 2016, 82, 285.

29. D. Geng, X. Bo, and L. Guo, Sens. Actuators, B, 2017, 244, 131.

30. S. Y. Park, Y. H. Kim, S. Y. Lee, W. Sohn, J. E. Lee, D. H Kim, Y.-S. Shim, K. C. Kwon, K. S. Choi, H. J. Yoo, J. M. Suh, M. Ko, J.-H. Lee, M. J. Lee, S. Y. Kim, M. H. Lee, and H. W. Jang, J Mater. Chem. A, 2018, 6, 5016.
31. Y. Li, H. Wang, L. Xie, Y. Liang, G. Hong, and H. Dai, J. Am. Chem. Soc., 2011, 133, 7296.

32. H. Song, Y. Ni, and S. Kokot, Biosens. Bioelectron., 2014, 56, 137.

33. E. B. Bahadır and M. K. Sezgintürk, TrAC, Trends Anal. Chem., 2016, 76, 1.

34. R. He, J. Hua, A. Zhang, C. Wang, J. Peng, W. Chen, and J. Zeng, Nano lett., 2017, 17, 4311.

35. L. Li, W. Zhang, X. Wang, S. Zhang, Y. Liu, M. Li, G. Zhu, Y. Zheng, Q. Zhang, T. Zhou, W. K. Pang, W. Luo, Z. Guo, and J. Yang, ACS Nano, 2019, 13, 7939.

36. Y. Chen, W. C. Peng, and X. Y. Li, Nanotechnology, 2017, 28, 205. 